\title{
FEM-DEM coupling simulations of the tool wear characteristics in prestressed machining superalloy
}

\author{
Peng Ruitao ${ }^{1 a}$, Tang Heng ${ }^{1,2}$, Tang Xinzi ${ }^{1}$ and Zhou Zhuan ${ }^{3}$ \\ ${ }^{1}$ Xiangtan University, Xiangtan, Hunan 411105, China \\ ${ }^{2}$ South China University of Technology, Guangzhou, Guangdong 510640, China \\ ${ }^{3}$ Hunan Nanfang Aviation Industry Co., Ltd, Zhuzhou, Hunan 412002, China
}

\begin{abstract}
Due to the complicated contact loading at the tool-chip interface, ceramic tool wear in prestressed machining superalloy is rare difficult to evaluate only by experimental approaches. This study aims to develop a methodology to predict the tool wear evolution by using combined FEM and DEM numerical simulations. Firstly, a finite element model for prestressed cutting is established, subsequently a discrete element model to describe the toolchip behaviour is established based on the obtained boundary conditions by FEM simulations, finally, simulated results are experimentally validated. The predicted tool wear results show nice agreement with experiments, the simulation indicates that, within a certain range, higher cutting speed effectively results in slighter wear of Sialon ceramic tools, and deeper depth of cut leads to more serious tool wear.
\end{abstract}

\section{Introduction}

Nickel-based superalloys are widely utilized in industrial application due to their excellent performance, as a hardto-machine material there's still a challenge to cut the alloy efficiently, prestressed cutting method has been validated as an efficacious way to control surface residual stress [1, 2], however characteristics of superalloy induce severe thermo-mechanical loads at the tool-chip interface which still result in significant wear of the tool.

Tool wear phenomena are complicate and experimental, analytical and numerical investigations are important keys to reveal the tool wear process and mechanism. In the last decade, experimental studies are performed to investigate the tool wear in machining superalloy. Rahman [3] explored the influence of cutting condition on the machinability of Inconel 718 by experiments. Kitagawa [4] investigated the temperature and wear of ceramic tools in high-speed machining of Inconel 718, boundary wear has been observed as the main form of tool wear. Costes [5] investigated the tool-life and wear mechanisms of CBN tools in machining of Inconel 718 and reported that the adhesion wear and diffusion wear were the main wear styles in the cutting process. These studies show that the influence of tool wear on machining process and more investigation are required.

More recently, with the rapid development of multicore CPU technique, numerical methods are widely used to study the cutting process beside the tool wear, such as finite element method (FEM), molecular dynamics (MD), discrete element method (DEM), and so on.
The FEM based on continuum mechanics, has already been widely used to solve tool abrasion problem. Yao [6] built a FEM model for studying the ceramic tool abrasion, effect of the physical properties such as hardness elastic modulus and fracture toughness to tool abrasion performance were researched, it's concluded that the higher of the hardness and elastic modulus, the higher of abrasion rate; and the higher of the fracture toughness, the lower of abrasion rate. Lorentzon [7] predicted the cutting force, chip thickness, cutting temperature, the contact stress and relative rate between chip and tool in cutting process via the FEM simulation, and rake face crater wear and flank wear were also analyzed. Monaghan [8] revealed the effect of rake angle on the tool wear via FEM simulations, and it's proved that negative rake angle may aggravate tool adhesion wear.

Discrete element method (DEM), evolved from molecular dynamics theory, which has widely been implemented in the study of geotechnics, concretes, ceramics and other brittle materials [9]. It shows great potential in simulating granular material and analyzing cracks. Tan [10] analyzed the mechanisms of the formation and propagation of cracks in machining $\mathrm{SiC}$ and $\mathrm{Al} 2 \mathrm{O} 3$ via DEM simulations; it indicates good agreement with the experimental validation. Fillot [11] provided a fundamental approach to study the wear process by considering the detachment of particles, the particles were judged whether they're in the contact zone or not, it's validated that discrete element method is feasible to simulate wear behavior. More recently, scientists have successfully utilized the DEM to study material's fracture, damage, 
wear behaviors and contact mechanics between rough surfaces [12-17].

The FEM-based method is capable to solve non-linear contact problem with reasonable accuracy and computational efficiency, however, it is lack of capability or qualification to reproduce the discontinuous behavior of material during cutting process, such as crack path and third body particles. The DEM has a practical potential to predict the evolution of crack initiation and propagation as well as the behavior of third body particles with high fidelity. However, the DEM is a time consuming algorithm in nature. Therefore, it is merely adopted to simulate assembly systems constructed by relatively small amount of elements. Considering the strengths and weakness of FEM and DEM for solving tool wear problem [18], a FEM-DEM coupled method is introduced here to research the ceramic tool abrasion behavior.

The aim of our current work is to develop a fundamental method to numerically analyze the wear problem taking into account the discontinuous behavior of ceramic tools. This paper is composed of five sections; In Section 2 an experimental setup was designed for prestressed machining superalloy. In Section 3, stress analysis of prestressed loading was performed, subsequently a finite element model for prestressed cutting superalloy was built and experimentally validated, and the contact stress between chip and tool, and the temperature distribution of tool as well as the speed of chip flow were extracted for the DEM models. In Section 4, a discrete element modeling technique was proposed and the microscopic parameters required in DEM simulations are determined and calibrated, effects of cutting factors and prestress on crack initiation and propagation were studied. And the DEM simulated results are validated by experimental studies. Finally, the paper was concluded in Section 5.

\section{Experimental work}

In our research, an experimental setup was carried out to verify the accuracy and feasibility of the FEM-DEM model. The tool-workpiece configuration, machining device and experimental setup used for measurements are illustrated in Figure. 1.

In order to load prestress to the workpiece, a special prestressed loading device is designed, as shown in Fig.1(a). The middle of fixture body and the inner circle of taper-lock are both conical shape and tapered consistently. To twist the nut on the right, the workpiece will be expanded. Moreover, a tailor-made workpiece is designed for orthogonal cutting to validate the FEM models.

The cutting tool is a rhombus uncoated insert, of a Sialon ceramic material, designated by CNGN120408, and is fixed on tool holder of the standard ISO designation DCLNR2525M12. KISTLER Model 9257B dynamometer is used to measure the three components of the cutting forces (main cutting force "tangential" Fc, feed force "axial" Ff, and depth of cut force "radial" Fp) during cutting tests. The basic geometry characteristics of Sialon ceramic cutting tools are listed in Table 1. The workpiece is a ring of the superalloy GH4169, with inner diameter of $40 \mathrm{~mm}$, and outside diameter of $60 \mathrm{~mm}$

Use A4 paper size $(210 \times 297 \mathrm{~mm})$ and adjust the margins to those shown in Table 1. The final printed area will be $172 \times 252 \mathrm{~mm}$.

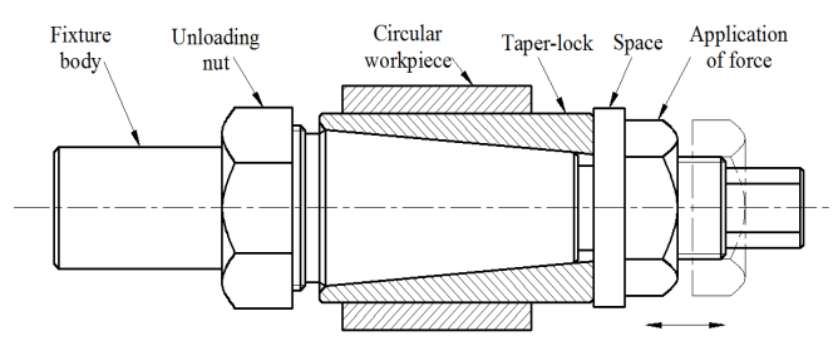

(a) Scheme of prestressed loading device

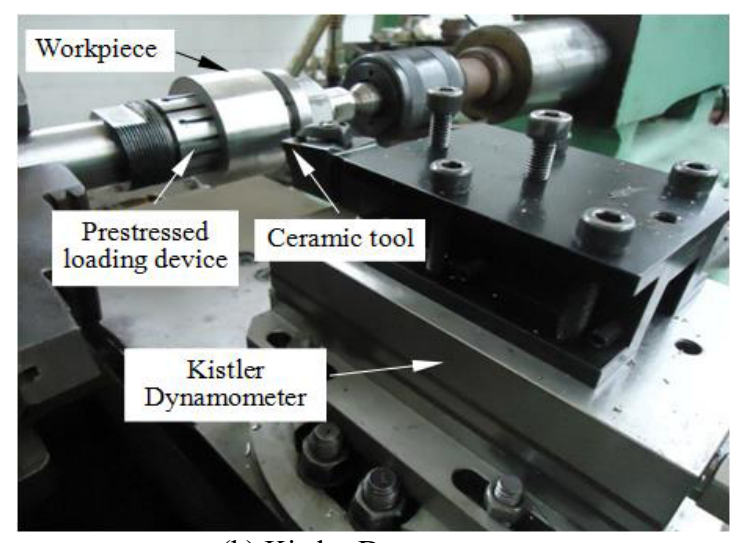

(b) Kistler Dynamometer

Figure 1. Experimental setup for machining

Table 1. Geometry characteristics of Sialon ceramic tools

\begin{tabular}{|c|c|c|c|c|c|}
\hline $\boldsymbol{\kappa}_{\mathrm{r}} /{ }^{\circ}$ & $\lambda_{\mathrm{S}}{ }^{\circ}$ & $\gamma_{0} /{ }^{\circ}$ & $\alpha_{0} /{ }^{\circ}$ & $\boldsymbol{\kappa}_{\mathrm{r}} / \rho^{\circ}$ & $\begin{array}{c}\text { Cutting nose radius } \\
r_{\varepsilon} / \mathrm{mm}\end{array}$ \\
\hline 95 & -6 & -6 & 6 & 5 & 0.8 \\
\hline
\end{tabular}

Aiming to reveal the influence of parameters including prestress, cutting speed, cutting depth on tool wear in prestressed cutting, single factor scheme, shown in Table 2, is designed for FEM simulations, DEM simulations and experimental validation.

Table 2. Single factor scheme

\begin{tabular}{|c|c|c|c|c|}
\hline Case & Prestress & Cutting speed & Cutting depth & Feed rate \\
\hline 1 & 0 & 90 & 0.2 & 0.2 \\
\hline 2 & 150 & 90 & 0.2 & 0.2 \\
\hline 3 & 300 & 90 & 0.2 & 0.2 \\
\hline 4 & 400 & 90 & 0.2 & 0.2 \\
\hline 5 & 400 & 30 & 0.2 & 0.2 \\
\hline 6 & 400 & 60 & 0.2 & 0.2 \\
\hline 7 & 400 & 130 & 0.2 & 0.2 \\
\hline 8 & 400 & 90 & 0.1 & 0.2 \\
\hline 9 & 400 & 90 & 0.3 & 0.2 \\
\hline 10 & 400 & 90 & 0.4 & 0.2 \\
\hline
\end{tabular}




\section{Finite element simulations}

\subsection{Constitutive model}

In order to accurately simulate the process of cutting superalloy using FE method, the material constitutive model must be calibrated to account for the material response under high strain rate impact. To analyze the machining process, a Johnson-Cook model [19] has been used to represent the thermo-viscoplastic behavior of GH4169, where the flow stress is given as follows:

$$
\sigma_{p}=\left(A+B \varepsilon_{p}^{n}\right)\left[1+C \ln \left(\frac{\dot{\varepsilon}_{p}}{\dot{\varepsilon}_{p 0}}\right)\right]\left[1-\left(\frac{T-T_{r}}{T_{m}-T_{r}}\right)^{m}\right]
$$

Where $\mathrm{A}$ and $\mathrm{B}$ are the material constants, $\mathrm{C}$ is the strain rate sensitivity, $\mathrm{n}$ is the strain-hardening, $\mathrm{m}$ is the thermal softening exponent, $\varepsilon p$ is the equivalent plastic

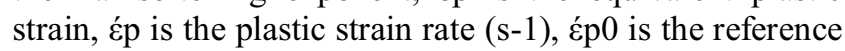
of plastic strain rate (s-1), $\mathrm{T}$ is the temperature, $\mathrm{Tm}$ is the material melting temperature and $\operatorname{Tr}$ is the reference temperature. The superalloy GH4169 parameters for Johnson-Cook model are given in Table 3.

Table 3. Johnson-Cook parameters of GH4169[20-21]

\begin{tabular}{|c|c|c|c|c|c|c|c|}
\hline $\begin{array}{c}A \\
(\mathrm{MPa})\end{array}$ & $\begin{array}{c}B \\
(\mathrm{MPa})\end{array}$ & $n$ & $C$ & $m$ & $\begin{array}{c}\dot{\varepsilon}_{\mathrm{p} 0} \\
\left(\mathrm{~s}^{-1}\right)\end{array}$ & $\begin{array}{c}T_{\mathrm{r}} \\
\left({ }^{0} \mathrm{C}\right)\end{array}$ & $\begin{array}{c}T_{\mathrm{m}} \\
\left({ }^{0} \mathrm{C}\right)\end{array}$ \\
\hline 1241 & 622 & 0.6522 & 0.0134 & 1.3 & 1 & 20 & 1297 \\
\hline
\end{tabular}

\subsection{FE modelling and boundary conditions}

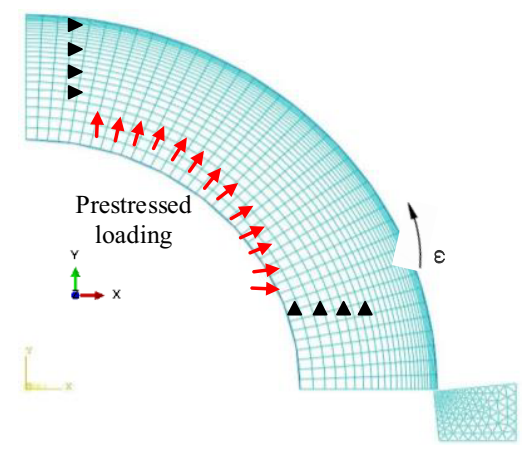

Figure 2. The FEM mesh model of prestressed cutting

The FE model of prestressed cutting is shown in Fig.2. Base on the method of prestress loading proposed by the author's previous literatures [1-2], the internal expansion method is adopt to load the prestress on the workpiece. Because of the stresses and displacements of the circular workpiece is axial symmetry, a quarter of the workpiece is considered to establish the model. The fixed constraint is applied to the horizontal and vertical boundary layers to prevent the rigid body movement. The cutting tool and workpiece are meshed with a plane strain coupled linear temperature-displacement 4 nodes element. Moreover, the outer ring of workpiece and cutting tool near of tool/workpiece contact zone are refined with a minimum element size. The cutting conditions are given in Table 2. The thermal boundary condition is the room temperature which is $27^{\circ} \mathrm{C}$.

\subsection{Model validation}

In order to validate the FE model for prestressed cutting, an orthogonal cutting experiment was designed base on the mentioned experimental setup in Section 2. In orthogonal prestressed cutting, measured cutting forces are compared with those obtained in FEM simulations. Influence of prestress, cutting speed and cutting depth on cutting force $\mathrm{Fc}$ and thrust force $\mathrm{Fp}$ are shown in Fig.3(a-c). It is observed that all the values of cutting forces predicted by FEM simulation are little lower than that in the experiment, and the overall trend of the simulated results shows a reasonably good agreement with the experimental results.

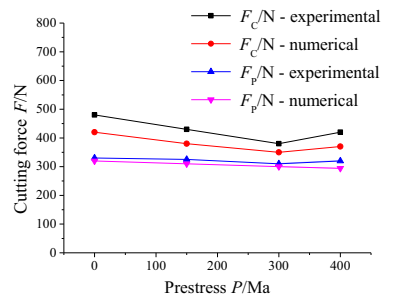

(a) Effect of prestress

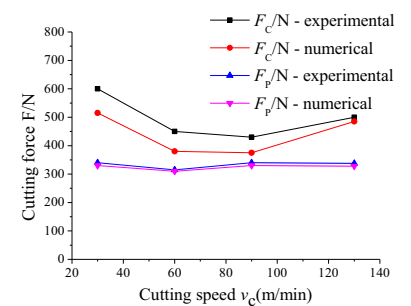

(b) Effect of cutting speed

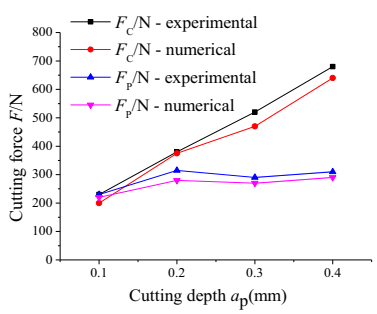

(c) Effect of cutting depth

Figure 3. Effect of cutting parameters on cutting force

As mentioned above, the simulation results of the cutting force have been found in good agreement with experimental results, considering the possible errors, the established FE models are deemed to be efficient and acceptable.

\subsection{Results}

The contact stress and contact length between tool and chip, temperature distribution of tool as well as speed of chip flow are obtained based on FEM simulations. The contact length between chip and tool is defined as the distance between the first nodal which commences to contact and the last nodal starts to detach.

The speed of the chip flow means the average velocity of the nodes of chip on the contact area while in steady cutting state. The velocities of the chip flow along the toolchip contact area are shown in Table 4.

The results indicate that the higher the cutting speed, the higher the chip velocity, and the values generally consistent with the theoretical calculation [22]. The theoretical formula is shown as follows:

$$
v_{c f}=\frac{v_{c} \sin \phi}{\cos \left(\phi-\gamma_{0}\right)}
$$


where $v_{c f}$ is the velocity of chip flow along the tool, $v_{c}$ means the cutting velocity, represents the shear angle, $\gamma_{0}$ is the rake angle of tool.

Table 4. Chip flow velocity based on FEM simulation

\begin{tabular}{|c|c|c|c|c|c|}
\hline Case & 1 & 2 & 3 & 4 & 5 \\
\hline $\begin{array}{c}\text { Chip flow velocity } \\
v_{c f} / \mathrm{m}^{\prime} \mathrm{min}^{-1}\end{array}$ & 1.04 & 1.12 & 1.12 & 1.12 & 0.38 \\
\hline \hline Case & 6 & 7 & 8 & 9 & 10 \\
\hline $\begin{array}{c}\text { Chip flow velocity } \\
v_{c f} / \mathrm{m}^{-1} \mathrm{~min}^{-1}\end{array}$ & 0.75 & 1.61 & 1.11 & 1.13 & 1.14 \\
\hline
\end{tabular}

The contact stresses between chip and tool extracted from the nodes on the tool's rake face are illustrated in Fig.4(a-k). From this figure, it is found that the maximum contact stress generally occurs approximately $0.02 \mathrm{~mm}$ from the tool tip. The contact stresses of the FEM model on the cut boundary are calculated by interpolating the FE simulated results. In DEM models, the nodal force will be specified as boundary condition for corresponding discrete element particle.

Fig.5 shows the temperature distribution of the tool. There is a decreasing temperature distribution trend along the thickness direction of the tool. The red folder line in the enlarged view is the temperature extraction path. The point-tracking temperature extracted from FEM simulations are shown in Table 5. It indicates that the highest nodal temperature and distribute tendency are varying with cutting conditions.

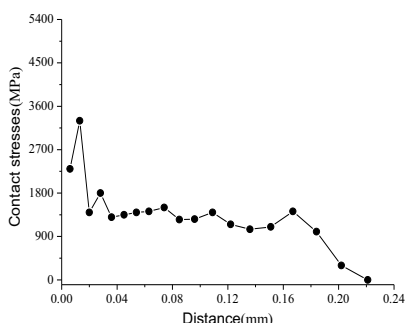

(a) Case1

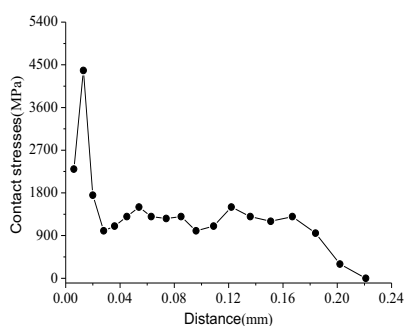

(c) Case 3

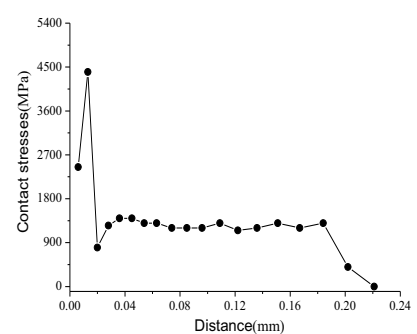

(e) Case 5

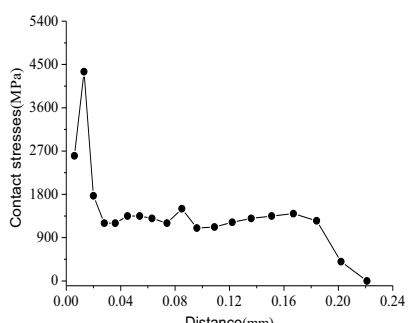

(b) Case 2

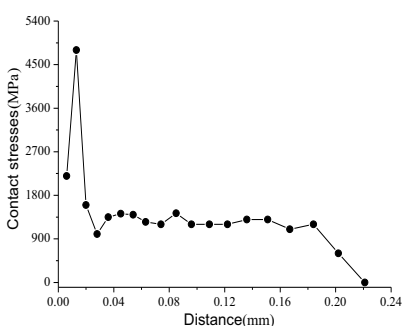

(d) Case4

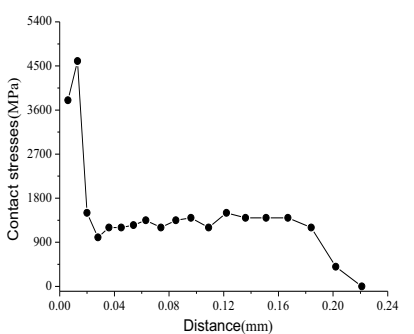

(f) Case6

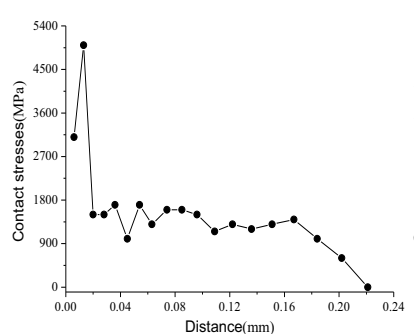

(g) Case 7

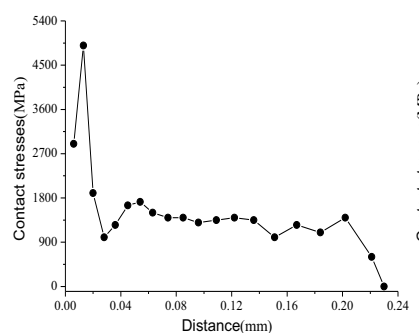

(j) Case9

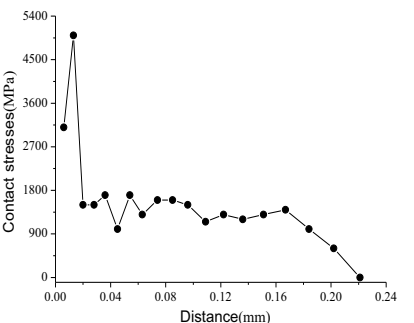

(h) Case 8

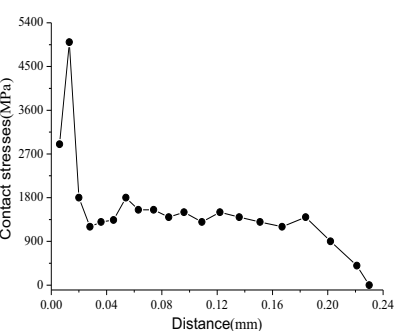

(k) Case10
Figure 4. The contact stresses of nodes in tool's rake face

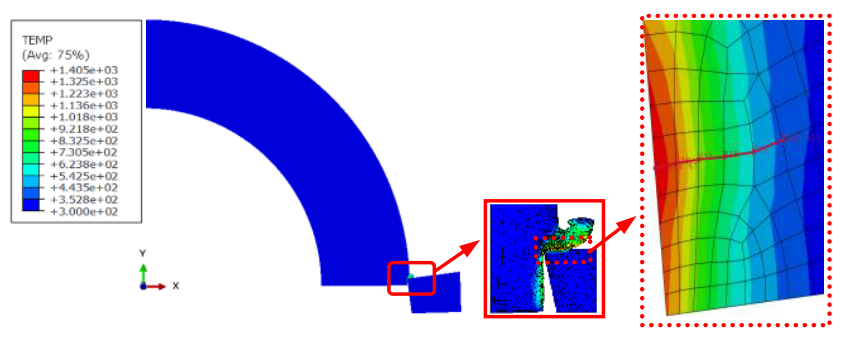

Figure 5. Temperature field of tool and extraction path $\left(/{ }^{\circ} \mathrm{C}\right)$

Table 5. Point-tracking temperature from FEM simulation

\begin{tabular}{|c|c|c|c|c|c|}
\hline Case & $\mathrm{TP}_{1}\left({ }^{\circ} \mathrm{C}\right)$ & $\mathrm{TP}_{2}\left({ }^{\circ} \mathrm{C}\right)$ & $\mathrm{TP}_{3}\left({ }^{\circ} \mathrm{C}\right)$ & $\mathrm{TP}_{4}\left({ }^{\circ} \mathrm{C}\right)$ & $\mathrm{TP}_{5}\left({ }^{\circ} \mathrm{C}\right)$ \\
\hline 1 & 962 & 852 & 756 & 667 & 584 \\
\hline 2 & 963 & 853 & 758 & 667 & 584 \\
\hline 3 & 964 & 855 & 758 & 668 & 586 \\
\hline 4 & 964 & 856 & 759 & 669 & 587 \\
\hline 5 & 880 & 829 & 783 & 737 & 692 \\
\hline 6 & 936 & 891 & 843 & 795 & 747 \\
\hline 7 & 1062 & 962 & 863 & 768 & 679 \\
\hline 8 & 894 & 842 & 791 & 740 & 692 \\
\hline 9 & 1054 & 953 & 857 & 767 & 683 \\
\hline 10 & 1073 & 958 & 855 & 762 & 676 \\
\hline
\end{tabular}

\section{Discrete element simulations}

In PFC2D software, the deformational behavior between units such as relative displacement generally can be realized by the parallel-bond to connect the joint. For continuous medium material, the parallel-bond glue is of a finite size that acts over either a circular or rectangular cross-section lying between the particles; it can transmit both forces and moments between particles. If either of the maximum stresses exceeds its corresponding bond strength, the parallel bond breaks and the particles break away from the contact area. Therefore, the damage of materials can be simulated by the connect bond's breakage 
between units. DEM method can dispose the procedure of materials' crack formation and propagation intuitively.

\subsection{Macro-parameters' Correction}

In order to match the established DEM model's mechanical property with the actual materials, it is necessary to adopt different mechanical model to adjust the DEM simulation macro-parameters (particle radius, particle stiffness, bond strength) [23]. The micro-parameter setting in the model is regarded reasonable when simulated results matched well with the practical material mechanics test value. Mechanical model such as uniaxial compression test, threepoint bending and single edge shearing and single edged notch beam were used to calibrate the macro-parameters of the ceramic material[24]. The calibrated results of Sialon ceramic material and GH4169 material are shown in Table 6 and Table 7 respectively [25].

Table 6. Simulated material properties of Sialon ceramic compared with referenced ones

\begin{tabular}{|c|c|c|c|}
\hline Mechanical Property & $\begin{array}{c}\text { Referenced } \\
\text { Result }\end{array}$ & $\begin{array}{c}\text { Simulated } \\
\text { Result }\end{array}$ & $\begin{array}{c}\text { Relative } \\
\text { Error }\end{array}$ \\
\hline Elastic Modulus/GPa & 300 & 305 & $1.6 \%$ \\
\hline Poisson ratio & 0.218 & 0.231 & $5.7 \%$ \\
\hline $\begin{array}{c}\text { Uniaxial compression } \\
\text { strength/MPa }\end{array}$ & 3600 & 3669 & $1.9 \%$ \\
\hline Bend strength/MPa & $750 \sim 1200$ & 1152 & - \\
\hline $\begin{array}{c}\text { Brittle strength } \\
\text { KIC/MPa } \cdot \mathrm{m}^{1 / 2}\end{array}$ & $5.5 \sim 6.0$ & 5.265 & $4.3 \%$ \\
\hline
\end{tabular}

Table 7. Simulated material properties of GH4169 compared with

\begin{tabular}{|c|c|c|c|}
\hline tested ones \\
Mechanical Property & $\begin{array}{c}\text { Tested } \\
\text { Result }\end{array}$ & $\begin{array}{c}\text { Simulated } \\
\text { Result }\end{array}$ & $\begin{array}{c}\text { Relative } \\
\text { Error }\end{array}$ \\
\hline Elastic Modulus/GPa & 206 & 192 & $6.8 \%$ \\
\hline Poisson ratio & 0.3 & 0.274 & $8.7 \%$ \\
\hline Bend strength/MPa & 1110 & 1208 & - \\
\hline $\begin{array}{c}\text { Brittle strength } \\
\text { KIC/MPa } \cdot \mathrm{m}^{1 / 2}\end{array}$ & 0.233 & 0.217 & $6.8 \%$ \\
\hline
\end{tabular}

\subsection{Temperature field}

Cutting temperature is an important factor which directly affects the cutting tool wear, workpiece surface integrity and machining precision in machining process. Kitagawa and Maekawak [4] utilized the embedded thermocouple method to determine the temperatures of Si3N4 ceramic tool rake face in machining of Inconel 718. The authors reported that the temperatures of tool rake face will reach $1100^{\circ} \mathrm{C}$ when the cutting speed over $100 \mathrm{~m} / \mathrm{min}$, and the higher temperature can aggravate the wear of tool. The influence of temperature is not considered in previous discrete element simulation of machining. It's known that the temperature of contact area in cutting nickel-based superalloy is much high and it has greater effects on the machinability of cutting tool and the workpiece, so the temperature field should be considered in the discrete element simulation. In this paper, the coupled thermomechanical models are established with the consideration of thermos influence on tool wear.

\subsection{The friction and wear model between tool and chip}

As mentioned before, the FEM simulation provides the boundary conditions for the DE model, including force boundary, temperature boundary and chip flow velocity.

The friction and wear model of tool and chip was established based on the simulated microcosmic parameters, the temperature distribution of the discrete element model was set according to the finite element simulation, and finally a coupled thermo-mechanical analysis was realized, as shown in Fig.6. In order to predict the friction and wear behavior between tool and chip in a limited size model, the chip's model was established by adopting the periodic boundary, namely, when a particle moves out of the system from the up side in y direction, consequently it will move into the system from the below side at the same time. The contact stresses extracted from FEM simulations were loaded on the right boundary of tool, the right boundary was modeled by vertically arranged assembly of discrete elements with unified radius. Contact pressure was imposed to the right wall (blue grain) of tool model (yellow grain), and the interpolated nodal stresses obtained from FEM simulations were applied to the corresponding discrete elements, note that a certain contact stresses between chip and tool should always be maintained. The chip (red grain) was given a constant upward flow velocity, which moved into the field from the below side of the periodic boundary, then flows along the tool surface, as soon as the particle arrived at the up side of the periodic boundary, it then break away from abrasion zone, and these particles then approach the below side of the periodic boundary repeatedly, the continuous movement from the below side to the up side of chip particles was achieved.

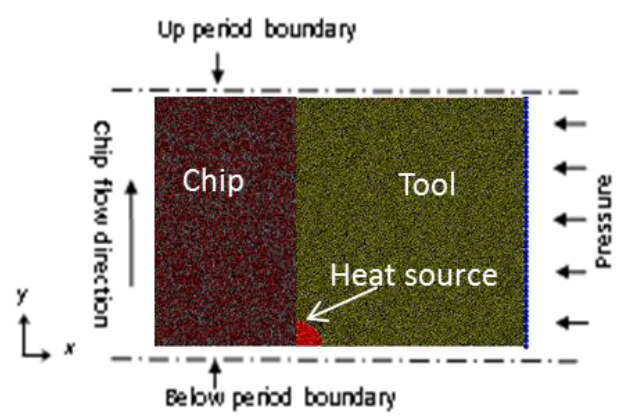

Figure 6. Tool-chip thermo-mechanical model

\subsection{Results and Analysis}

The DEM simulation results are shown in Figure. 7 and Figure.8, the white curves refers to the detached particles, which are named cracks in the cutting process, it is convenient to analyze the concealed cracks of the tool, the tool's crack produced in the rake face can be observed distinctly which has a certain distance to the tool tip, and it gradually extends to the inner layer until to the rear face, consequently lamellar exfoliation is occurred on the tool tip. The tip of tool prone to wear when the force loaded on tool tip exceeded the limited value. 
The simulated results under different cutting speed are presented in Figure.7. From these pictures, it is found that breakup and exfoliation of tool tip increase with cutting speed to a maximum first achieved at the speed of 90 $\mathrm{m} / \mathrm{min}$ and then decreasing. In other words, tool wear is the most serious at the speed of $90 \mathrm{~m} / \mathrm{min}$. Figure. 8 shows the simulation results under different cutting depth. The results represent that the crack length and the peeling area produced in the tool tend to be increased with the increase of cutting depth. Figure.10 illustrates the simulated results of tool wear under different prestress. It can be seen that tool wear shows more serious without prestress than that with prestress. In addition, within a certain range, the tool wear will be ameliorated with the increase of prestress.

The contact surface between tool and chip exists microcracks and deciduous particles (gray particle), which are shown in Figure.9. Shedding particle are mingled with the two contact surface, the wear form between chip and tool turns into 3-body wear state [26] and this layer of particles intensifies the wear of tool.

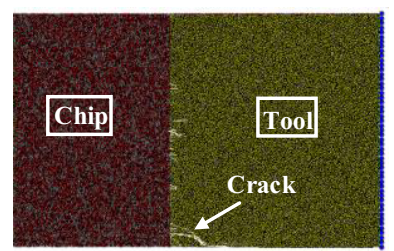

(a) Case5

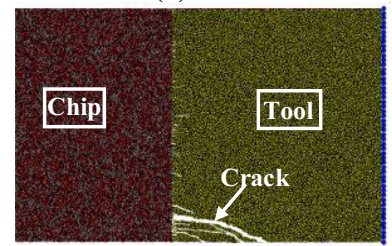

(c) Case 4

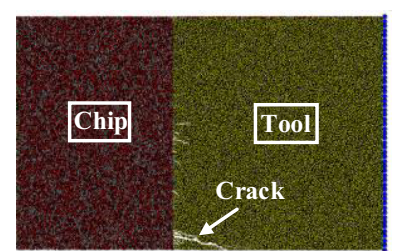

(b) Case6

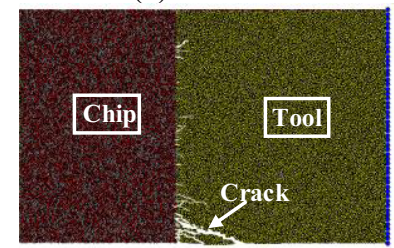

(d) Case 7
Figure 7. DE simulation of tool wear under different cut speeds $\left(P=400 \mathrm{MPa}, a_{\mathrm{p}}=0.2 \mathrm{~mm}, f=0.2 \mathrm{~mm} / \mathrm{r}\right)$

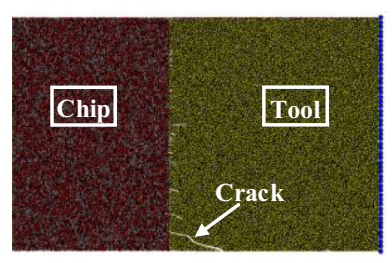

(a) Case 8

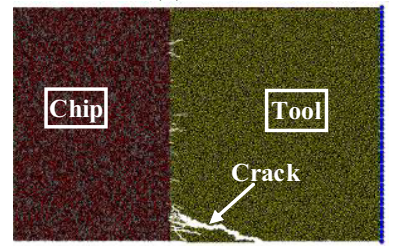

(c) Case9

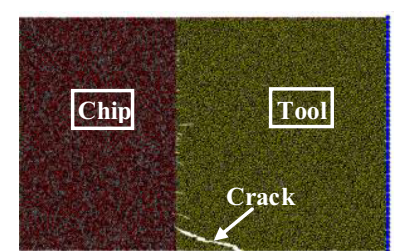

(b) Case 4

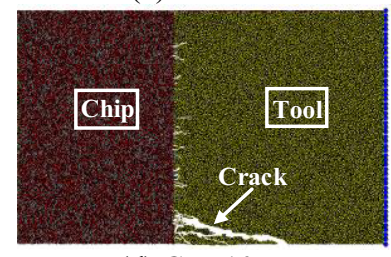

(d) Case 10
Figure 8. DE simulation of tool wear under different cut depths $\left(P=400 \mathrm{MPa}, v_{\mathrm{c}}=90 \mathrm{~m} / \mathrm{min}, f=0.2 \mathrm{~mm} / \mathrm{r}\right)$

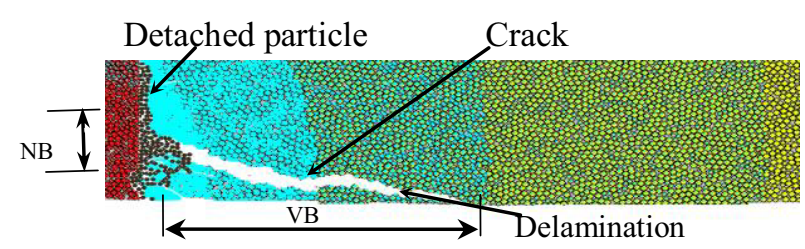

Figure 9. Partial enlargement of cracks in Fig.8. (c)

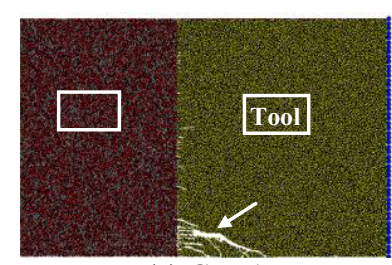

(a) Case 1

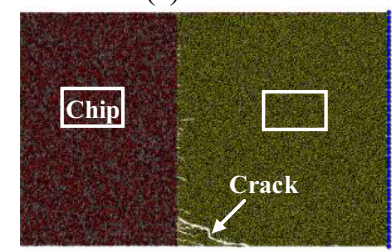

(c) Case 3

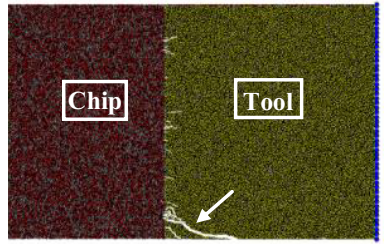

(b) Case2

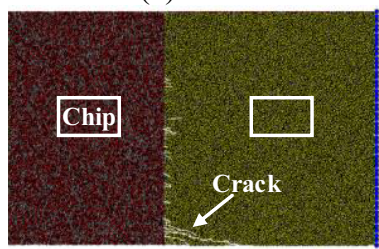

(d) Case4
Figure 10. DE simulation of tool wear under different prestress $\left(a_{\mathrm{p}}=0.2 \mathrm{~mm}, v_{\mathrm{c}}=90 \mathrm{~m} / \mathrm{min}, f=0.2 \mathrm{~mm} / \mathrm{r}\right)$

Figure. 11 clearly shows the number of peeled particle from tool and the number of micro-crack, which are calculated automatically by the software, vary along with the cutting speed at the cutting depth of $0.2 \mathrm{~mm}$. It suggests that with the increase of cutting speed, cutting tool microcrack number and particle peeling number were increased first and then decreased. The main reason is that as cutting speed increased to a certain range, the increase of temperature in workpiece will result in the mollification of workpiece [27-28], and the cutting force is reduced with the decreased strength and stiffness of workpiece. Meanwhile, the increased cutting temperature improves the friction deformation between chip and tool, thereby leads to the decreased of the additional deformation and chip outflow resistance in the area.

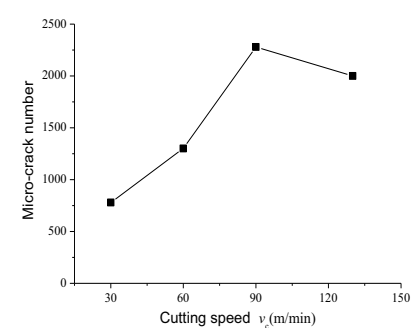

(a) Micro-crack number

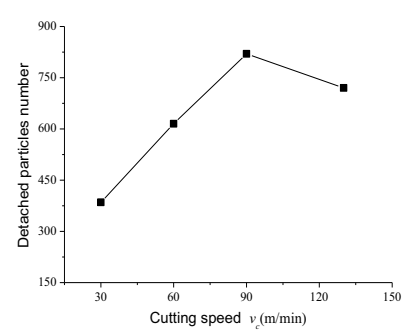

(b) Detached particles number
Figure 11. Effect of cutting speed on micro-crack number, detached particles number and wear rate

The number of shedding particles and micro crack of tool vary with the cutting depth are shown in Figure.12. It's noted that the number of shedding particles and micro cracks increase with the increase of cutting depth. It further explains that increased cutting depth can aggravate the damage of tool.

The number of shedding particles and micro crack of tool vary with the prestress are presented in Fig.13. It is shown from Fig.13 that, as the prestress increases, the number of shedding particles and micro cracks initially decrease and then begin to stabilize. From these results it is clearly seen that, within a certain range, the prestress conditions present effective wear resistance of flank wear. 


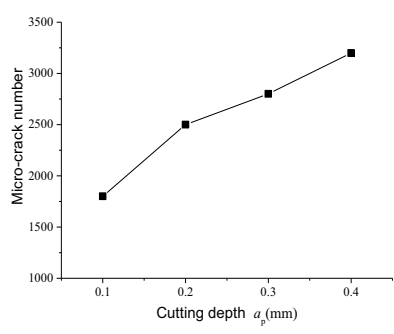

(a) Micro-crack number

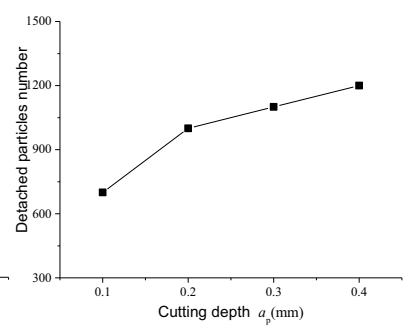

(b) Detached particles number

Figure 12. Effect of cut depth on micro-crack number, detached particles number and wear rate

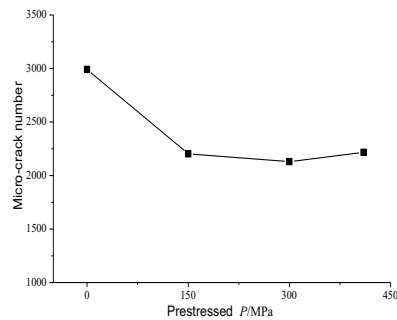

(a) Micro-crack number

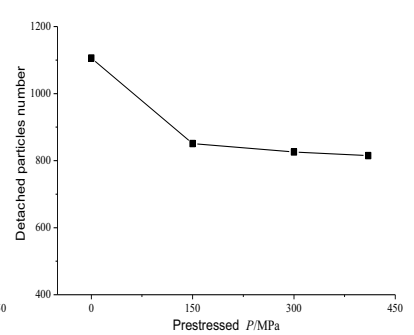

(b) Detached particles number
Figure 13. Effect of prestress on micro-crack number, detached particles number and wear rate

\subsection{Model validation}

According to the experiment and DEM simulation, the influence of cutting depth, cutting speed and prestress on tool flank wear (VB) are revealed. The measured results and predicted values are compared in Fig. 14.

It can be observed that the cutting depth has greatest influence on the tool flank wear. And the value of VB increases with the increases of cutting depth. Meanwhile, it can also be found that the tool flank wear increase with cutting speed to a maximum first achieved at the speed of $90 \mathrm{~m} / \mathrm{min}$ and then decreasing. Both FEM results and experimental results indicate that prestress conditions are beneficial to mitigate the tool flank wear. As shown in Fig.14, the overall trend of the simulated results shows a reasonably good agreement with the experimental results, the established DE models are deemed to be acceptable as an efficient tool to predict tool wear in prestressed machining superalloy.

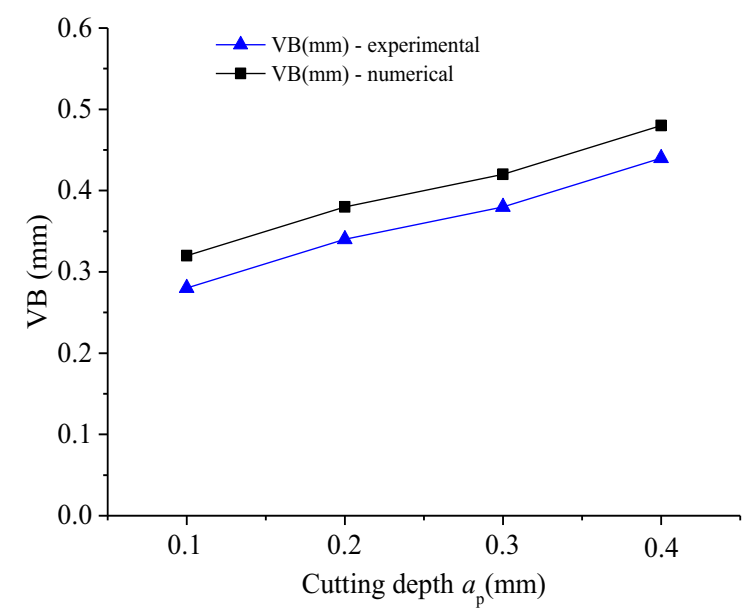

(a) Effect of cutting depth

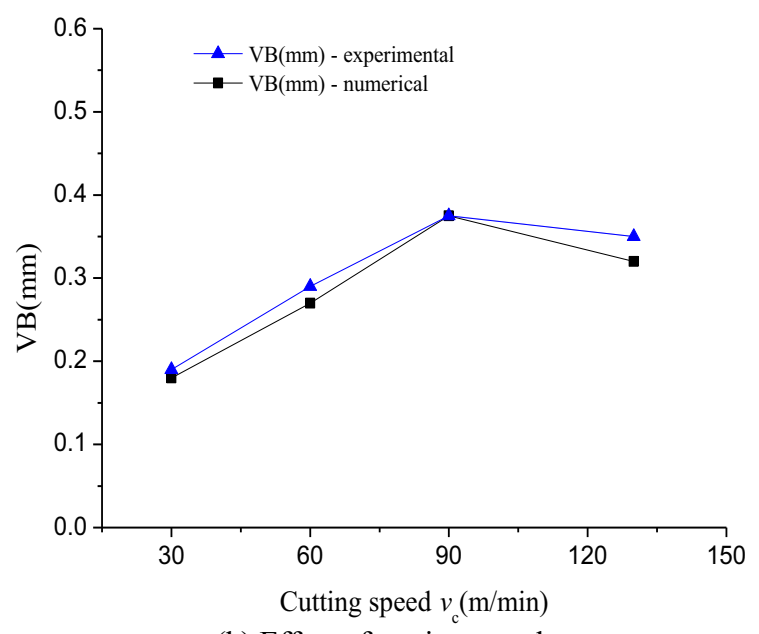

(b) Effect of cutting speed

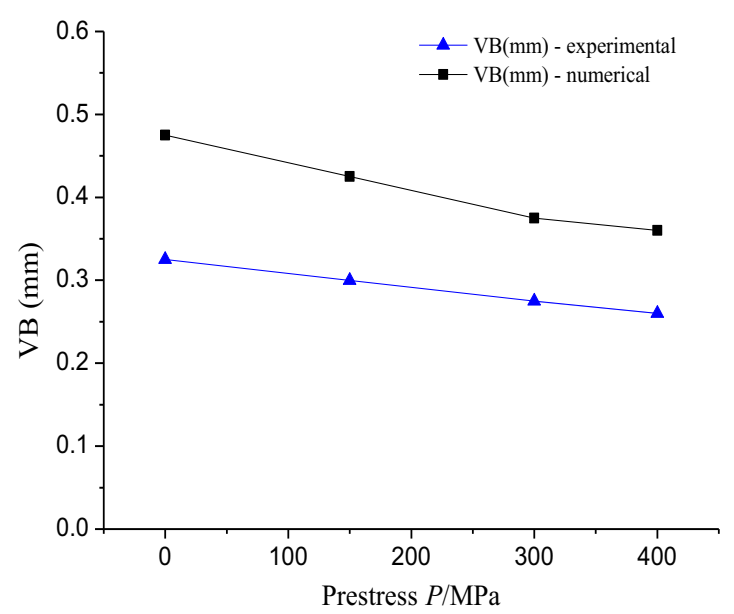

(c) Effect of cutting prestress

Figure 14. Effect of the cutting parameters on tool wear

\section{Conclusions}

Through combined FEM-DEM simulation and experimental validation, this paper discusses the ceramic tool wear behavior in prestressed machining superalloy GH4169. According to results presented in this paper, the following conclusions can be addressed:

(1) A finite element model of the prestressed cutting process is established on the basis of the prestress loading mechanism and validated by orthogonal cutting experiments, the contact stress and contact length between tool and chip, temperature distribution of tool as well as speed of chip flow in steady cutting state are obtained based on FEM simulations, which provide necessary boundaries for DEM models.

(2) The inter-element contact constitutive model as well as corresponding microscopic parameters are determined and calibrated to describe continuous and discontinuous behaviors of material in DEM simulation. The discrete element model of tool-chip wear was established, effect of prestress, cutting depth and cutting speed on tool wear were simulated and also validated by experiments under different cutting conditions, and the simulated results were consistent with the experiment results. The both results show that the combined FEM-DEM methodology is an efficient tool to qualitatively and quantitatively analyze the 
tool wear behavior, especially in simulating the generation of the micro-crack and delamination.

(3) Within a certain range, prestress conditions are beneficial to mitigate the tool flank wear, higher cutting speed effectively results in slighter wear of ceramic tool, and deeper depth of cut leads to more serious tool wear.

\section{Acknowledgments}

This study was supported by the Joint Fund of Provincial Natural Science Foundation between Hunan Province and Zhuzhou City (13JJ8007), and also funded by the National Natural Science Foundation of China (No. 51475404, No.51375418, No. 51305377), and the Foundation of Hunan Educational Committee (No. 14B166).

\section{References}

1. R.T. Peng, X.Z. Tang, Y.Q. Tan, X.W. Liu. Finite Proc. Ame. Inst. Phys, 1532, 962-968 (2013).

2. R.T. Peng, M. Liao, X.Z. Tang, Y.Q. Tan, X.W. Liu. J. Mech. Engi, 19, 186-191 (2012).

3. M. Rahman, W.K.H. Seah, T.T. Teo. J. Mate. Proc. Tech, 63, 199-204 (1997).

4. T. Kitagawa, A. Kubo, K. Maekawa. Wear, 202, 142148 (1997).

5. J.P. Costes, Y. Guillet, G. Poulachon, et al. Int. J. Mach. Tool. Manu, 47, 1081-1087 (2007).

6. S.Q. Yao, S.M. Xing, J.X. Deng. Tribol. Int, 26, 566569 (2006)

7. J. Lorentzon, N. Jarvstrat. J. Mach. Tool. Manu, 48, 1072-1080 (2008).

8. J. Monaghan, T. Macginley. Comp. Mater. Sci, 16, 275-284 (1999).

9. S.Q. Jiang, Y.Q. Tan, S.J. Nie, et, al. J. Inorg. Mater, 25, 1286-1290 (2010).

10. Y.Q. Tan, D.M. Yang, Y. Sheng. J. Eur. Ceram. Soc, 29, 1029-1037 (2009).

11. N. Fillot, I. Iordanoff, Y. Berthier. Tribol. Int, 40, 973981 (2007).

12. M. Nouari, I. Iordanoff. Tribol. Int, 40, 1351-1359 (2007).

13. Y.Q. Tan, D.M. Yang, Y. Sheng. J. Eur. Ceram. Soc, 29, 1029-1037 (2009).

14. J.F. Jerier, J.F. Molinari. Tribol. Int, 47, 1-8 (2012).

15. A. Delaplace. Geomech. Geoengin, 4, 79-89 (2009).

16. I. Iordanoff, A. Battentie, J. Neauport, et al. Tribol. Int, 41, 957-64 (2008).

17. D. Andre, I. Lordanoff, J.L. Charles, et al. Comp. Methods Appl. Mech. Engrg, 213, 113-25 (2012).

18. B.D. Leonard, P. Patil, T.S. Slack, et al. J. Tribol-the ASME, 133, 1-12 (2011).

19. G. Johnson, W. Cook. Engin. Fracture. Mech, 2, 3148 (1985)

20. P.J. Arrazola, A. Kortabarria, A. Madariaga, et al. Pract. Th, 41, 87-103 (2014).

21. J. Lorentzon, N. Järvstråt, B.L. Josefson. J. Mater. Process. Tech, 209, 4645-4653 (2009).

22. M.E. Merchant. J. Appl. Phys, 16, 267-275 (1945).

23. D.O. Potyondy, P.A. Cundall. Int. J. Rock. Mech. Min. Sci, 41, 1329-1364 (2004).
24. S.Q. Jiang, Y.Q. Tan, D.M. Yang, et al. J. Chin. Ceram. Soc, 5, 918-923 (2010).

25. R.T. Peng, F. Lu, X.Z. Tang, Y.Q. Tan. Mater. Sci. Forum, 800-801, 385-389 (2014).

26. M. Godet. Wear, 100, 437-452 (1984).

27. J. Zhao, J. Deng, J. Zhang, et al. Wear, 208, 220-225 (1997).

28. E. Oñate, J. Rojek. Comput. Methods. Appl. Mech. Engrg, 193, 3087-3128(2004). 